\title{
COVID-19 Prevention Practices and Associated Factors Among Frontline Community Health Workers in Jimma Zone, Southwest Ethiopia
}

\author{
Tadesse Gebremedhin (1D) \\ Habtamu Abebe iD ' \\ Wondimagegn Wondimu (iD) ${ }^{2}$ \\ Abraham Tamirat Gizaw (D) ${ }^{3}$ \\ 'Department of Epidemiology, Faculty of \\ Public Health, Jimma University, Jimma, \\ Ethiopia; ${ }^{2}$ Mizan-Tepi University, College \\ of Medicine and Health Sciences, \\ Department of Epidemiology and \\ Biostatistics, Mizan Aman, Ethiopia; \\ ${ }^{3}$ Department of Health Behaviour and \\ Society, Faculty of Public Health, Jimma \\ University, Jimma, Ethiopia
}

\begin{abstract}
Background: A timely understanding of the frontline community health care workers' prevention practices towards COVID-19 is very crucial to combat the pandemic. Despite this, no study has been conducted among frontline community health workers in Africa, particularly in Ethiopia. The study aimed to determine the status of implementation of preventive measures of frontline community health care workers towards COVID-19 and its associated factors.
\end{abstract}

Methods: An institution-based cross-sectional study was conducted on 421 health extension workers among selected districts. Data were collected using a pretested structured questionnaire adapted from different pieces of literature. Respondents who scored above mean score on the item measurement such as knowledge, attitude, and practice questions were categorized as knowledgeable, having positive attitude, and having good prevention practices, respectively. Data were entered in EpiData 3.1 and analyzed using Statistical Package for Social Sciences (SPSS) version 23.0 software. A multivariable logistic regression model was used to identify significant predictors. $\mathrm{P}-$ values less than or equal to 0.05 were declared as statistically significant.

Results: The mean age of study participants was 31.35 years $( \pm 4.83 \mathrm{SD})$, and almost half $(217 ; 51.54 \%)$ of respondents were single and $273(62.47 \%)$ were trained for COVID-19 prevention measures. Of the total study subjects, $194(46.08 \% ; 95 \% \mathrm{CI}=41.6-50.7 \%)$ had good prevention practices towards COVID-19. Being married (AOR=3.36, 95\% $\mathrm{CI}=2.20-5.13$ ), being trained ( $\mathrm{AOR}=2.28,95 \% \mathrm{CI}=1.39-3.74)$, having good knowledge ( $\mathrm{AOR}=2.4,95 \% \mathrm{CI}=1.52-3.99)$, and having positive attitude towards COVID-19 prevention measures $(\mathrm{AOR}=5.88,95 \% \mathrm{CI}=3.52-9.80)$ increase the likelihood of implementing prevention measures.

Conclusion: This study showed that prevention status was low; therefore, government and non-governmental organizations working around the study area should emphasize providing training to increase their level of knowledge and to change the attitude towards implementation of prevention measures, and these can ultimately increase the status of prevention practices.

Keywords: prevention practices, frontline community health workers

\section{Introduction}

The coronavirus disease-19 (COVID-19) pandemic has caused enormous stress among the public in China initially and then after the whole world. ${ }^{1,2}$ This pandemic has had several impacts on global economy, political activities and human health in general due to lockdown strategies. Different evidence has suggested that
Correspondence: Tadesse Gebremedhin Email tadessegw1983@gmail.com 
new strategies like strengthening implementation of preventive measures should be established rather than the lockdown strategy as this strategy encouraged economic crises. ${ }^{2,3}$ Amidst the current pandemic, the WHO has issued several guidelines and also started online courses and training sessions to raise awareness and preparedness regarding prevention and control of COVID-19 among health care workers. In addition to the WHO, the Ethiopian public health institute also published several recommendations for health care workers aimed to reduce the occupational spread of infection among health care workers.

During the COVID-19 pandemic community health workers have played a major role by assisting COVID19 surveillance data, contact tracing and ensuring that the community is implementing WHO preventive measures. ${ }^{2,4}$

In Ethiopia, community health workers have a long history, dating back to around the time of the 1978 Alma Ata Conference on Primary Health Care. These health workers were selected by their communities to receive training on basic health care services. Around the 1990s the Ethiopian ministry of health shifted its health priority from a curative approach to a preventive approach. This approach gave emphasis for rural inhabitants who make up $85 \%$ of the total Ethiopian population. The role of community health workers in Ethiopia was targeted for these massive rural people for prevention of health and promoting of health of the community at large beyond providing basic health services currently. Community health workers in Ethiopia are now serving the community by providing health information on how to control pandemics, protect themselves from different diseases and even how to cope with disasters/epidemics. ${ }^{2,5,6}$ For such valuable strategies to be effective, the status of frontline community health workers' prevention measure should be known and gave response accordingly to save other community.

The Health Extension Program (HEP) serves as an effective mechanism for shifting health care resources from predominantly urban to rural areas, where more than $85 \%$ of the country's population lives. Therefore, the health extension program could be considered as the most important national framework to improve the health status of the community by emphasizing preventive measures. Under this program, health extension workers are working in the community as frontline community health workers. ${ }^{6,7}$

A practice survey provides a suitable format to evaluate existing programs and to identify effective strategies for behavior change in society. ${ }^{8-10}$ Although educational campaigns have increased their awareness regarding COVID19, the evidence of implementation of preventive measures is limited. ${ }^{8,9,11,12}$ Despite the knowledge and a positive attitude towards coronavirus prevention, different studies revealed that most health care workers in different settings were not practicing appropriately. ${ }^{13-18}$ Evidence from Nigeria showed that the status of implementation of preventive measures among community health care workers and other health care providers together totaled $42 \%$. The possible factors associated with such poor practices were also reported as lack of training and poor attitude towards preventive measures. Strengthening frontline community health worker's knowledge on implementation of prevention practices is the only option to reduce/control the pandemic due to the lack of curative activities, as well as these individuals are very close to the community for awareness creation to the community as a whole. ${ }^{6}$ Higher attention should be given to these frontline health care workers than other health care workers because they are fully engaged in the primary health care unit and their primary aim is disease prevention and health promotion at home-to-home level. Different studies conducted in different settings among different health care workers reported that coronavirus knowledge, positive attitude, training, working site, and sex were significantly associated with self-reported prevention practices. $^{13,19}$

The status of preventive practices on coronavirus among frontline health workers is still unknown globally and in Ethiopia particularly. Filling gaps of frontline health workers means filling gaps of the communities, because they are giving care for the community daily by moving from hometo-home. This study will be a baseline for other studies as it is the first study in our continent specifically for frontline community health workers. On top of this, this study saves our scarce resources and we can easily address our community by determining the level of prevention practices of frontline health workers. The main aim of this survey was the assessment of prevention practices of frontline health workers and associated factors towards coronavirus disease in Jimma zone, southwest Ethiopia.

\section{Methods and Materials Research Setting, Sample, Data Collection, and Quality Control}

The study was conducted in eight selected Districts of Jimma zone. Jimma zone is one of the zones of the 
Oromia Region in Ethiopia. The zone has 20 districts. According to the data taken from the Jimma zone health department, all health extension workers are females and the ratio of kebeles to health extension workers in the zone was estimated to be $2: 5$.

The source population for this study was all health extension workers working in the districts of the Jimma zone. All health extension workers working in the districts of the Jimma zone and who have fulfilled the inclusion criteria were the study population. The inclusion criteria used to recruit the study population was having worked more than 6 months in the study area.

The sample size was determined by using the singlepopulation proportion formula by using the following assumptions: 95\% confidence level, 5\% margin of error, and $50 \%$ proportion of good practice towards COVID-19 prevention measures (since there were no comparable studies). After considering the $10 \%$ non-response rate, the final calculated sample size became 424 .

$$
\begin{gathered}
\mathrm{n}=\frac{\left[\mathrm{Z}_{\frac{\alpha}{2}}\right]^{2} \mathrm{pq}}{\mathrm{d}^{2}} \\
\mathrm{n}=\frac{[1.96]^{2} 0.50 *[1-(0.50)]}{(0.05)^{2}}=384 \\
\mathrm{n}_{\mathrm{f}}=\mathrm{n}+10 \% *(\mathrm{n})
\end{gathered}
$$

where $\mathrm{n}_{\mathrm{f}}=384+39, \mathrm{n}_{\mathrm{f}}=423$.

From the 20 districts, eight districts (Shebe, Omo Nada, Kersa, Mana, Tiro Afeta, Dedo, Seka Chekorsa and Sokoro districts) were selected by lottery method. The frames were obtained from districts and using the number of eligible frontline community health workers in each district, samples (numbers of subjects from each districts to participate) were allocated proportionally. Then codes were given to each eligible subject and the final study participants were selected using a simple random sampling technique from each district.

The questionnaire was translated to the local language (Oromiffa) by language experts and collected by using a self-administered questionnaire. This translated questionnaire was also back-translated to English to check its consistency. During data collection, data collectors have used COVID-19 prevention measure protocols like face masks, sanitizer, and keeping their physical distance.

To ensure data quality; the questionnaire was pre-tested on $5 \%$ (25 frontline community health workers) of the calculated sample size a week before the actual data collection period in another district of Jimma zone. Based on findings of the pretest, necessary modifications were done on the instrument. One day training was given for eight data collectors and four supervisors concerning the objectives of the study and to have a common understanding. The reliability of the tool was checked and the result of Cronbach's alpha was above the acceptable range.

Ethical approval was provided from the ethical review board of Jimma University Institute of Health (reference number $=$ IHRPGD/877/20). This approved ethical letter was submitted to the Zonal health Department for permission. Zonal health Department gave us the permission letter for all of the eight districts. The districts confirmed our letter of permission and then the data collector took permission to collect data from frontline community health workers. After explaining the overall objectives of the study, study subjects were asked for their consent to participate. We obtained informed oral consent from each study subject, which was approved by the ethical review board of Jimma University Institute of Health. The respondents' right to refuse or withdraw from participating at any time was fully respected and the information provided by each respondent was kept confidential by making each questionnaire coded and not sharing personal information of any patient to the third party. After obtaining their oral consent, data collectors gave them the questionnaire. The study was conducted according to the Declaration of Helsinki.

\section{Measures of Variables}

The knowledge tool contains 12 yes/no items with the overall score ranging between $0-12$. An individual who scored less than the mean score was categorized as with poor knowledge and one who scored as mean or above was categorized as having good knowledge. ${ }^{20}$ Attitude was assessed by 10 Likert scale items (very low, low, moderate, high and very high) with a minimum score of 10 and maximum score of 50. For attitude variable, an individual who scored less than the mean score was categorized as having negative attitude and one who scored mean and above was categorized as having positive attitude. $^{20}$ For preventive practice questions we used 11 Likert scale questions (never, rarely, sometimes, often, and always) with a minimum score of 11 and a maximum score of 55. Finally an individual who scored less than the mean was classified as having poor prevention 
practices and one who scored mean and above was classified as having good prevention practices respectively. ${ }^{16}$

\section{Study Design and Data Analysis Procedure}

A community-based cross-sectional study design was employed from January 1 to February 5, 2021. The data were exported from Epidata version 3.1 to SPSS version 21 for analysis. In the descriptive analysis, items such as mean, standard deviation, frequency, and percentages were calculated for continuous variables. Univariate and bivariate analyses were employed before multivariable analysis. All independent variables were considered for bivariable logistic regression and five variables (age, marital status, training status, knowledge, and attitude status) were candidates for multivariable logistic regression analysis.

In the analytic statistics, binary logistic regression was used by considering prevention practices as the outcome variable. Variables whose $p$-value was less than 0.25 in bivariate logistic regression were eligible for multiple logistic regression analysis. Variables whose $p$-value was less than 0.05 in multiple logistic regression analyses were considered significant. Accordingly, all independent variables were entered into bivariable logistic regression one by one and five of them (age, marital status, training status, knowledge, and attitude) were candidates for multivariable logistic regression analysis. The measure of association we used for this study was OR with its $95 \%$ confidence interval. The model goodness of fit was checked by Hosmer Lemeshow's goodness of fit and reported a $p$-value $=0.215$, which means good to fit.

\section{Result}

\section{Socio-Demographic and Other Characteristics of the Participants}

The study included 421 health extension workers, making the response rate $99.3 \%$. The average age $\pm \mathrm{SD}$, monthly income $\pm \mathrm{SD}$, and work experience $\pm \mathrm{SD}$ of study participants were $31.35 \pm 4.83$ years, $5,367.73 \pm 1,555.42$ ETB, and $8.96 \pm 3.97$ years, respectively. From the total study participants, more than half $(51.54 \%)$ of them were married and the majority $(63.66 \%)$ of them were working in rural kebeles. The majority $(71.97 \%)$ of the study participants were Muslims followed by Orthodox (19.71\%) and around one-fourth of study participants had an
Table I Sociodemographic and Other characteristics of Frontline Community Health Workers in Jimma Zone, 202I $(n=42 I)$

\begin{tabular}{|l|l|l|l|}
\hline Variables & Categories & Numbers & $\%$ \\
\hline Marital status & Single & 217 & 51.54 \\
& Married & 187 & 44.42 \\
& Others & 17 & 4.038 \\
\hline Residence & Rural & 268 & 63.66 \\
& Urban & 153 & 36.34 \\
\hline Religion & Orthodox & 83 & 19.71 \\
& Muslim & 303 & 71.97 \\
& Protestant & 33 & 7.838 \\
\hline Educational status & Certificate & 107 & 25.42 \\
& Diploma & 299 & 71.02 \\
& Degree and & 15 & 3.563 \\
\hline Status of training on COVID- & above & & \\
\hline 19 prevention measures & Yes & 148 & 37.53 \\
\hline
\end{tabular}

Note: a'Divorced, widowed.

educational level of certificate. More than one-third (37.53\%) of the study participants did not take any training related to preventive measures towards COVID-19 (Table 1).

The majority $(315 ; 74.82 \%)$ of study subjects gained information from television, followed by radio (257; $61.05 \%$ ) (Table 2).

The majority of study participants had good knowledge and almost $60 \%$ of study participants had a positive attitude towards preventive measures. Regarding practices towards preventive measures, less than half, $(194 ; 46.08 \%)$ of the study participants had a relatively good practice status (Figure 1).

Table 2 Sources of Information on Preventive Practices of Frontline Community Health Workers of Jimma Zone Towards COVID-I9, $2021(n=421)$

\begin{tabular}{|c|c|c|}
\hline Source of Information & Frequency & $\%$ \\
\hline Television & 315 & 74.82 \\
\hline Radio & 257 & 61.05 \\
\hline Health educator & 236 & 56.06 \\
\hline Internet and social media & 197 & 46.79 \\
\hline Co-workers & 153 & 36.34 \\
\hline Health care workers & 141 & 33.49 \\
\hline Neighbors and friends & 75 & 17.81 \\
\hline Newspaper & 63 & 14.96 \\
\hline
\end{tabular}




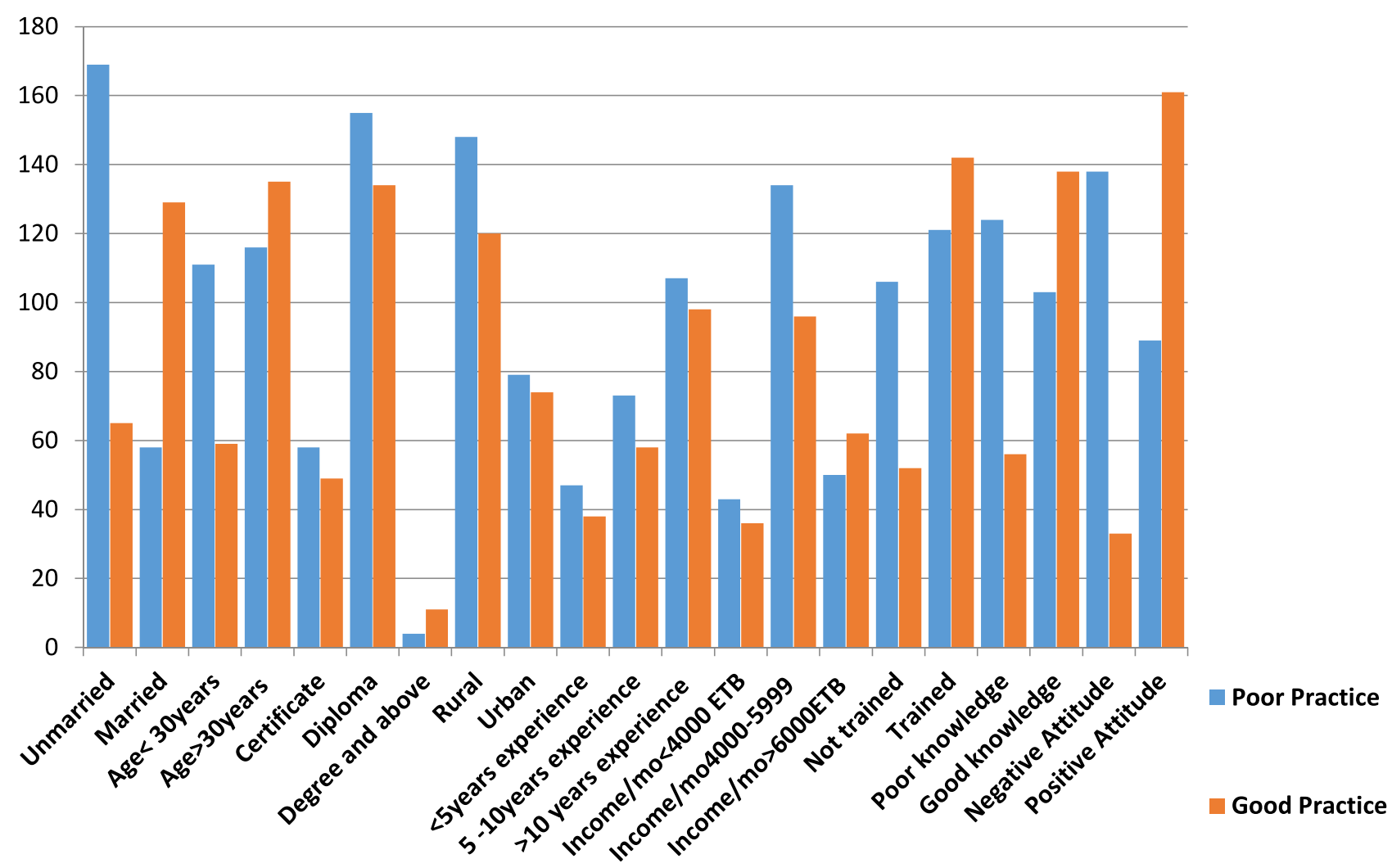

Figure I Description of independent variables with preventive practices towards COVID-I9 among frontline community health workers in Jimma zone, 202I ( $=42$ I).

\section{COVID-19 Prevention Practices of the Study Participants}

This report showed that only $11.4 \%$ of the interviewed participants always washed or disinfected their hands. Regarding face mask utilization, very few (4.51\%) participants always used their face masks, while $23 \%$ never used face masks. Among the total respondents, only $6 \%$ of them avoided handshaking, and $41 \%$ of the respondents never stop handshaking. From interviewed participants, more than half $(54.4 \%)$ of them never kept their physical distances and only $20(4.75 \%)$ always kept the recommended physical distance to prevent transmission. Of the participants, $11.6 \%$ never followed the news about prevention towards COVID-19, while around 20\% always followed the news regarding prevention measures per week (Table 3). This finding shows that 194 (46.08\%) of frontline health workers have good preventive practices and the remaining 227 (53.92\%) were categorized as having poor preventive practices.

The odds of implementing prevention practices of COVID-19 was 3.36 (95\% CI=2.20-5.13) times higher among married frontline community health workers compared to unmarried ones. The odds of implementing prevention practices of COVID-19 was 2.28 (95\% $\mathrm{CI}=1.39-3.74)$ times more likely in trained frontline community health workers than those who did not take any training regarding COVID-19 preventive measures.

The odds of good COVID-19 prevention practice was 2.46 (95\% CI $=1.52-3.99)$ times more likely among those who had good knowledge than those who had poor knowledge regarding COVID-19 preventive measures.

Finally, the odds of implementing prevention practices towards COVID-19 among frontline community health workers was $6 \quad(\mathrm{AOR}=5.88 ; 95 \% \mathrm{C}=3.52-9.80)$ times higher among those who had a positive attitude towards COVID-19 prevention measures compared to those who had a negative attitude (Table 4).

\section{Discussion}

This study assessed the magnitude and factors associated with preventive practices of Jimma zone frontline health workers towards COVID-19. During COVID-19 pandemic, all community health care workers, including frontline health workers, have to implement different preventive measures 
Table 3 Prevention Status of Frontline Health Workers Measured by Specific Items Towards COVID- 19 in Jimma Zone, 202I ( $\mathrm{n}=42 \mathrm{I}$ )

\begin{tabular}{|c|c|c|c|c|c|c|c|c|c|c|}
\hline & \multicolumn{2}{|l|}{ Never } & \multicolumn{2}{|l|}{ Rarely } & \multicolumn{2}{|c|}{ Sometimes } & \multicolumn{2}{|l|}{ Often } & \multicolumn{2}{|l|}{ Always } \\
\hline & Count & $\%$ & Count & $\%$ & Count & $\%$ & Count & $\%$ & Count & $\%$ \\
\hline How often do you wash or disinfect your hands? & 34 & 8.08 & 86 & 20.43 & 104 & 24.7 & 149 & 35.39 & 48 & 11.4 \\
\hline $\begin{array}{l}\text { How often do you avoid touching your face and eyes } \\
\text { with unwashed hands? }\end{array}$ & 28 & 6.65 & 55 & 13.06 & 153 & 36.34 & 164 & 38.95 & 21 & 4.99 \\
\hline How often do you use a face mask? & 96 & 22.8 & 158 & 37.53 & 80 & 19 & 68 & 16.15 & 19 & 4.51 \\
\hline $\begin{array}{l}\text { How often do you use a face mask, paper tissue, or } \\
\text { elbow when sneezing, coughing, or having a runny nose? }\end{array}$ & 70 & 16.6 & 128 & 30.4 & 135 & 32.07 & 63 & 14.96 & 25 & 5.94 \\
\hline $\begin{array}{l}\text { How often do you throw your used face masks and } \\
\text { tissue papers in separate bags and then in a bin? }\end{array}$ & 75 & 17.8 & 117 & 27.79 & 95 & 22.57 & 71 & 16.86 & 63 & 15 \\
\hline $\begin{array}{l}\text { How often do you regularly disinfect surfaces of } \\
\text { personal objects and places? }\end{array}$ & 63 & 15 & 89 & 21.14 & 105 & 24.94 & 138 & 32.78 & 26 & 6.18 \\
\hline How often do you shake hands with others? & 25 & 5.94 & 16 & 3.8 & 47 & 11.16 & 160 & 38 & 173 & 41.1 \\
\hline How often do you kiss others? & 98 & 23.3 & 168 & 39.9 & 53 & 12.59 & 84 & 19.95 & 18 & 4.28 \\
\hline How often do you hug others? & 238 & 56.5 & 69 & 16.39 & 44 & 10.45 & 50 & 11.88 & 20 & 4.75 \\
\hline $\begin{array}{l}\text { How often do you keep at least a } 2 \text { meter distance } \\
\text { from others? }\end{array}$ & 229 & 54.4 & 87 & 20.67 & 32 & 7.601 & 53 & 12.59 & 20 & 4.75 \\
\hline $\begin{array}{l}\text { How often do you follow the news about COVID-19 per } \\
\text { week? }\end{array}$ & 49 & 11.6 & 145 & 34.44 & 66 & 15.68 & 80 & 19 & 81 & 19.2 \\
\hline
\end{tabular}

recommended by WHO. Even though the disease prevalence is increasing exponentially on a day-to-day basis, not all communities have implemented the recommendations. ${ }^{21,22}$ To our knowledge, this study was the first study in our country (Ethiopia) which assessed the proportion of preventive practices implemented by frontline health workers towards COVID-19. This study revealed that only 194 (46.08\%) of the study participants had a good preventive practice status. Our finding reported $46.08 \%$ with a $95 \%$ CI of $41.6-50.7 \%$, which is a nearly consistent finding with astudy done in Northwest Ethiopia, which showed that the magnitude of good practice of health care workers was $38.73 \%(95 \% \mathrm{CI}=34.8-42.5){ }^{23}$ On the other hand this study was in agreement with a study done in Nigeria, which reported that $42 \%$ of health care workers had good preventive practices. $^{2}$

This study finding was lower than studies conducted in the Amhara region, Tigray region, Uganda, China, Umm AlQura University, and Mozambique, which showed that $62 \%$, $72 \%, 74 \%, 89.7 \%, 89.7 \%$, and $84 \%$ of health care providers had good preventive practices, respectively. ${ }^{18,21,24-27}$ These discrepancies can be justified as the differences in study participants' level of education, as the study subjects who participated in prior studies were health care workers who were at least diploma nurses. The evidence from Amhara region supported that educational level influences the level of implementation of preventive practices. ${ }^{21}$ The other possible justifications for this disagreement might be the study period; the prior studies were conducted at the beginning of the emergence of the pandemic and at that time the majority of people were implementing preventive measures regardless of their knowledge and attitude, but currently, even though there is plenty of information towards COVID-19, most of the people are not implementing them properly, as evidence from studies done show the magnitude of prevention status rapidly decreased from $89.7 \%$ to $38 \%$ within 6 months. ${ }^{21,23,24,26}$

This study showed that married frontline health workers had significantly better preventive practices towards COVID-19 than unmarried. This study was in line with a study done in the northwest part of Ethiopia which reported that the odds of good practice in married study participants was 3.9-times higher than unmarried participants. ${ }^{16}$ Some studies reported that preventive measure status among married and unmarried were equal. The studies conducted in Jimma University Medical Center visitors and the North central part of Ethiopia showed that marital status did not affect implementation of preventive practices. ${ }^{22,28}$ This disagreement might be the difference in sample size, which was done only among 247 study participants in Jimma and 182 in Northern Ethiopia. ${ }^{22,28}$

Several studies have supported that training was directly related with prevention practices. ${ }^{17,18,27-31}$ The current study shows that the odds of implementing good preventive 
Table 4 Factors Associated with Preventive Practices Towards COVID-I 9 Among Frontline Health Workers in Jimma Zone, 202I ( $\mathrm{n}=42 \mathrm{I}$ )

\begin{tabular}{|c|c|c|c|c|c|}
\hline \multirow[t]{2}{*}{ Variables } & \multirow[t]{2}{*}{ Categories } & \multicolumn{2}{|c|}{ Practice Status } & \multirow[t]{2}{*}{ COR $(95 \% \mathrm{Cl})$} & \multirow[t]{2}{*}{ AOR $(95 \% \mathrm{CI})$} \\
\hline & & Poor & Good & & \\
\hline \multirow[t]{2}{*}{ Marital status } & Unmarried $^{\mathrm{a}}$ & 169 & 65 & 1 & 1 \\
\hline & Married & 58 & 129 & $5.78(3.79-8.82)^{b}$ & $3.36(2.20-5.13)^{\mathrm{b}}$ \\
\hline \multirow[t]{2}{*}{ Age in years } & $<30$ years & III & 59 & & \\
\hline & $\geq 30$ years & 116 & 135 & $2.19(1.46-3.27)^{\mathrm{b}}$ & $1.38(0.79-2.43)$ \\
\hline \multirow[t]{3}{*}{ Educational status } & Certificate & 58 & 49 & I & 1 \\
\hline & Diploma & 155 & 134 & $0.96(0.62-1.50)$ & $0.73(0.4 I-I .29)$ \\
\hline & Degree and above & 4 & II & $3.25(0.97-10.87)$ & $1.77(0.45-4.00)$ \\
\hline \multirow[t]{2}{*}{ Residence } & Rural & 148 & 120 & I & 1 \\
\hline & Urban & 79 & 74 & I.I5 (0.78-I.72) & $1.19(0.72-1.98)$ \\
\hline \multirow[t]{3}{*}{ Work experience } & $<5$ years & 47 & 38 & & \\
\hline & $5-10$ years & 73 & 58 & $0.98(0.57-1.70)$ & $2.03(0.98-4.19)$ \\
\hline & $\geq 10$ years & 107 & 98 & $1.13(0.68-1.88)$ & $1.18(0.6 \mathrm{I}-2.27)$ \\
\hline \multirow[t]{3}{*}{ Monthly Income (ETB) } & $<4,000$ ETB & 43 & 36 & I & I \\
\hline & $4,000-5,999$ & 134 & 96 & $0.85(0.5 \mathrm{I}-\mathrm{I} .43)$ & $0.73(0.36-I .5 I)$ \\
\hline & $\geq 6,000$ ETB & 50 & 62 & $1.48(0.83-2.64)$ & $1.00(0.44-2.3)$ \\
\hline \multirow[t]{2}{*}{ Training } & No & 106 & 52 & & \\
\hline & Yes & 121 & 142 & $2.39(1.58-3.61)^{b}$ & $2.28(1.39-3.74)^{c}$ \\
\hline \multirow[t]{2}{*}{ Knowledge status } & Poor knowledge & 124 & 56 & 1 & I \\
\hline & Good knowledge & 103 & 138 & $2.96(1.98-4.45)^{\mathrm{b}}$ & $2.46(1.52-3.99)^{\mathrm{b}}$ \\
\hline \multirow[t]{2}{*}{ Attitude } & Negative & 138 & 33 & 1 & 1 \\
\hline & Positive & 89 & 161 & $7.56(4.77-1 \mathrm{I} .98)^{\mathrm{b}}$ & $5.88(3.52-9.80)^{\mathrm{b}}$ \\
\hline
\end{tabular}

Notes: a'Single, divorced and widowed, ${ }^{b}$ Significant at $p$-value $<0.00$ I, ${ }^{c}$ significant at $p$-value $<0.05$. Hosmer Lemeshow goodness of model fit $p$-value $=0.215$.

Abbreviations: COR, crude odds ratio; AOR, Adjusted odds ratio.

practice in trained frontline community health workers were 2.26-times better than in individuals who did not take any training regarding COVID-19. This report is in agreement with studies done in Amhara region, Ethiopia and Ghana, which showed that the odds of good practices were more likely in trained individuals than participants who had not received any training toward COVID-19. ${ }^{21,32}$ Therefore, training has a great role to improve prevention practices.

The current study revealed that knowledge of frontline community health workers is positively associated with implementing preventive practices. It reported that the odds of good preventive practices of COVID-19 in knowledgeable participants was 2.54-times more likely than participants who had poor knowledge. This report was supported by evidence from Ethiopia, Ghana, Nepal, and Saudi Arabia. ${ }^{15,20,21,32}$ This agreement might be as stated in several studies; knowledge is the basis of any form of applications like implementing preventive practices. This could also be explained by the awareness they access from different information sources, media, and experts which improves their level of practices. ${ }^{12,14}$ Generally, to practice specific recommended activity we have to have adequate awareness or full knowledge, as suggested in different studies. ${ }^{12,14,17,20}$

The attitude of a human being is the result of his/her judgment towards something. ${ }^{33}$ After evaluation, the majority of individuals who judged something as positive, practice the event well and those who evaluate it negatively are less likely to implement it well. ${ }^{23}$ From this point of view, our study supported such facts and reported that the odds of good preventive practice in participants who have positive attitudes was 5.88-times more likely than participants who have negative attitudes. This finding was in line with several studies conducted in different parts of Ethiopia, Saudi Arabia, China, and Egypt. ${ }^{13,17-20,23,26,27}$

This study has several limitations like the subjectivity nature of the instrument might cause an overestimation of the magnitudes of knowledge, attitude, and practice 
statuses. The nature of the study design itself limited us to estimate the cause-effect relationship. On top of these limitations, the study used valid, reliable instruments, and took an adequate sample size by addressing eight districts in the zone.

\section{Conclusion}

The magnitude of preventive practices of frontline health workers in the zone is encountered as low. A poor preventive practice was reported among unmarried, poorly knowledgeable, untrained, and participants who have a negative attitude towards prevention measure recommendations. As the disease was exponentially increasing from day to day basis; stakeholders like the regional health bureau and the zone health department as well as specific district health offices should give special attention to improve their knowledge and change the attitude towards prevention measures. Improving frontline community health workers' prevention status is basic to save other communities as a whole because their roles were totally within the community. Jimma zone health department and other stakeholders should give training for those who have not taken it yet and assess their status regularly.

\section{Abbreviations}

COVID-19, coronavirus disease 2019; KAP, knowledge, attitude, and practice; WHO, World Health Organization.

\section{Data Sharing Statement}

The data were available from the corresponding author upon request.

\section{Acknowledgments}

We would like to thank Jimma University for providing us the ethical clearance. We acknowledged the data collectors and study participants for their participation.

\section{Author Contributions}

All authors contributed to data analysis, drafting or revising the article, gave final approval of the version to be published, agreed to the submitted journal, and agree to be accountable for all aspects of the work.

\section{Funding}

No specific fund was obtained to conduct this study.

\section{Disclosure}

The authors declare that they have no competing interests.

\section{References}

1. World Health Organization. Novel Coronavirus (2019-Ncov) Situation Report - 5 (25 January 2020). WHO Bull; 2020:1-7.

2. Coccia M. knowledge and practice of Kaduna state health care providers on infection prevention and control of COVID-19 pandemic. JMBSR. 2021;1:27-41.

3. Qin X, Godil DI, Khan MK, et al. Investigating the effects of COVID-19 and public health expenditure on global supply chain operations: an empirical study. Oper Manag Res . 2021. doi:10. 1007/s12063-020-00177-6

4. Bezbaruah S, Wallace P, Zakoji M, Padmini Perera WS, Kato M. Roles of community health workers in advancing health security and resilient health systems: emerging lessons from the COVID-19 response in the South-East Asia Region. WHO South East Asia J Public Health. 2021;10:41. doi:10.4103/22243151.309872

5. Bhutta ZA, Lassi ZS, Pariyo G, Huicho L. Global Experience of Community Health Workers for Delivery of Health Related Millennium Development Goals: A Systematic Review. Country Case Studies and Recommendations for Integration into National Health Systems. Vol. 2013. Karachi, Pakistan: WHO; 2013:1-377.

6. Banteyerga H. Ethiopia's health extension program: improving health through community involvement. MEDICC Rev. 2011;13: 46-49.

7. Wang H, Tesfaye R, Ramana GNV, Chekagn CT. Ethiopia Health Extension Program an Institutionalized Community Approach for Universal Health Coverage; 2016.

8. Coman C, Țîru LG, Meseșan-Schmitz L, Stanciu C, Bularca MC. Online teaching and learning in higher education during the coronavirus pandemic: students' perspective. Sustain. 2020;12:1-22. doi:10. 3390/su122410367

9. Hailu D, Benayew M, Liknaw T, et al. Occupational health safety of health professionals and associated factors during covid-19 pandemics at north showa zone, oromia regional state, ethiopia. Risk Manag Healthc Policy. 2021;14:1299-1310. doi:10.2147/RMHP. S292830

10. Graciaa DS, Machaidze M, Kipiani M, et al. A survey of the tuberculosis physician workforce in the country of Georgia. Int $J$ Tuberc Lung Dis. 2018;22:1286-1292.

11. Shihaji W. Ethiopian national emergency report of COVID 19. in Health Bulletin; 2020.

12. Nations U, Office A. Competency-based approach to technical and vocational education and training in Africa Competency-based approach to technical and vocational education.

13. Al-hazmi A, Gosadi I, Somily A, Alsubaie S, Bin A. Knowledge, attitude and practice of secondary schools and university students toward Middle East Respiratory Syndrome epidemic in Saudi Arabia: a cross-sectional study. Saudi J Biol Sci. 2018;25:572-577. doi:10.1016/j.sjbs.2016.01.032

14. Al-Mohaissen M. Awareness among a Saudi Arabian university community of Middle East respiratory syndrome coronavirus following an outbreak. East Mediterr Health J. 2017;23:351-360. doi:10.26 719/2017.23.5.351

15. Shrestha A, Bhattarai D, Thapa B, Basel P, Wagle RR. Health care workers ' knowledge, attitudes and practices on tuberculosis infection control, Nepal. BMC Infect Dis. 2017;1-7. doi:10.1186/s12879-0172828-4

16. Akalu Y. Knowledge, attitude and practice towards COVID-19 among chronic disease patients at Addis Zemen Hospital, Northwest Ethiopia. Infect Drug Resist. 2020;13:1949-1960.

17. Shi Y, Wang J, Yang Y, Wang Z, Wang G. Knowledge and attitudes of medical staff in Chinese psychiatric hospitals regarding COVID-19. Brain Behav Immun. 2020;4:100064. 
18. Elamin F. Knowledge, attitude and practices of healthcare providers towards MERS-CoV infection at Makkah hospitals, KSA self-esteem and alienation in parents having children with intellectual disability. View project knowledge, attitude and practices of healthcare. Int Res $J$ Med Med Sci. 2015;3:103-112.

19. Alsahafi AJ, Cheng AC. Knowledge, attitudes and behaviours of healthcare workers in the Kingdom of Saudi Arabia to MERS coronavirus and other emerging infectious diseases. Int $J$ Environ Res Public Health. 2016;1-8. doi:10.3390/ijerph13121214

20. Khan MU, Shah S, Ahmad A, Fatokun O. Knowledge and attitude of healthcare workers about middle east respiratory syndrome in multispecialty hospitals of Qassim, Saudi Arabia. BMC Public Health. 2014;13:1-7.

21. Asemahagn MA. Factors determining the knowledge and prevention practice of healthcare workers towards COVID-19 in Amhara region, Ethiopia: a cross-sectional survey. Trop Med Health. 2020;48:1.

22. Kebede Y, Yitayih Y, Birhanu Z, Mekonen S, Ambelu A. Knowledge, perceptions and preventive practices towards COVID-19 early in the outbreak among Jimma university medical center visitors, Southwest Ethiopia. PloS One. 2020;77:1-15.

23. Kassie BA, Adane A, Kassahun EA, Ayele AS, Belew AK. Poor COVID-19 preventive practice among healthcare workers in Northwest Ethiopia, 2020. Adv Public Health. 2020;2020.

24. Olum R, Chekwech G, Wekha G, Nassozi DR, Bongomin F. Coronavirus disease-2019: knowledge, attitude, and practices of health care workers at Makerere University Teaching Hospitals, Uganda. Front Public Health. 2020;8:1-9.

25. Feldman M, Lacey Krylova V, Farrow P, et al. Community health worker knowledge, attitudes and practices towards COVID-19: learnings from an online cross-sectional survey using a digital health platform, UpSCALE, in Mozambique. PLoS One. 2021;16(2):1-11. doi:10.1371/journal.pone.0244924
26. Zhang M, Zhou M, Tang F. Knowledge, attitude, and practice regarding COVID-19 among healthcare workers in Henan, China. J Hosp Infect. 2020;105(2):183-187

27. Tadesse DB, Gebrewahd GT, Demoz GT. Knowledge, attitude, practice and psychological response toward COVID-19 among nurses during the COVID-19 outbreak in northern Ethiopia, 2020. New Microbes New Infect. 2020;38:100787. doi:10.1016/j.nmni.2020.100787

28. Birihane BM, Bayih WA, Alemu AY, Belay DM. Perceived barriers and preventive measures of COVID-19 among healthcare providers in Debretabor, North Central Ethiopia. Risk Manag Healthc Policy. 2020;13:2699-2706. doi:10.2147/RMHP.S287772

29. Wogayehu B, Taye W, Chisha Y, Faraja K. Knowledge regarding 2019 novel coronavirus (2019-nCoV) infection among final year health science students at Arbaminch College of Health Sciences, Southern Ethiopia: a cross - sectional study.

30. Wahed WY, Hefzy EM, Ahmed MI, Hamed NS. Assessment of knowledge, attitudes, and perception of health care workers regarding COVID - 19, a Cross - Sectional Study from Egypt. J Community Health. 2020;45(6):1242-1251. doi:10.1007/s10900-020-00882-0

31. Article R. Challenges and opportunities to tackle COVID-19 spread in Ethiopia. J Peer Sci. 2020;2:e1000014.

32. Nkansah C, Serwaa D, Adarkwah LA, et al. Novel coronavirus disease 2019: knowledge, practice and preparedness: a survey of healthcare workers in the offinso-north district, Ghana. Pan Afr Med J. 2020;35 (Supp 2):1-6. doi:10.11604/pamj.supp.2020.35.2.23644

33. Caroline N. Teachers attitude towards implementation of learner-centered methodology in science education in Kenya. Educ Res Rev. 2017;12:996-1007. doi:10.5897/ERR2017.3326
Journal of Multidisciplinary Healthcare

\section{Publish your work in this journal}

The Journal of Multidisciplinary Healthcare is an international, peerreviewed open-access journal that aims to represent and publish research in healthcare areas delivered by practitioners of different disciplines. This includes studies and reviews conducted by multidisciplinary teams as well as research which evaluates the results or conduct of such teams or healthcare processes in general. The journal covers a very wide range of areas and welcomes submissions from practitioners at all levels, from all over the world. The manuscript management system is completely online and includes a very quick and fair peer-review system. Visit http://www.dovepress.com/testimonials. php to read real quotes from published authors. 